\title{
The use of sequential probabilities in the segmentation of speech
}

\author{
ARIE H. VAN DER LUGT \\ Exeter University, Exeter, England
}

\begin{abstract}
The present investigation addresses the possible utility of sequential probabilities in the segmentation of spoken language. In a series of five word- spotting and two control lexical decision experiments, high- versus low-probability consonant-vowel (Experiments 1, 2, 5, and 7) and vowel-consonant (Experiments $1,3,4$, and 6 ) strings were presented either in the nonsense contexts of target words (Experiments 1-3) or within the target words themselves (Experiments 4-7). The results suggest that listeners, at least for sequences in the onset position, indeed use sequential probabilities as cues for segmentation. The probability of a sound sequence influenced segmentation more when the sequence occurred within the target words (Experiments 4-7 vs. Experiments 1-3). Furthermore, the effects were reliable only when the sequences occurred in the onset position (Experiments 1, 2, 5, and 7 vs. Experiments 1, 3, 4, and 6).
\end{abstract}

"To wreck a nice beach" or "To recognize speech"? Ambiguities like this, where the latter utterance can be mistaken for the former, show that the boundaries between words are not reliably marked in speech (Klatt, 1976; Lehiste, 1972; Nakatani \& Dukes, 1977; Quené, 1992). However, in order to understand spoken language, the listener has to segment the continuous speech stream into discrete units that convey the meaning of an utterance - that is, into words. People use several strategies to deal with this problem of segmentation.

Although spoken language does not contain the clear demarcation of word boundaries that is provided by spaces in written language, there are several sources of information that can be used, when available, to parse the speech stream into words. Long silences, acoustic-phonetic cues (Gow \& Gordon, 1995; Lehiste, 1972; Nakatani \& Dukes, 1977; Quené, 1989, 1992, 1993), phonological restrictions (e.g., vowel harmony in Finnish: Suomi, McQueen, \& Cutler, 1997; Vroomen, Tuomainen, \& de Gelder, 1998), phonotactics (McQueen, 1998), and metrical cues (Cutler, Mehler, Norris \& Segui, 1986, for French; Cutler \& Norris, 1988, for English; Otake, Hatano, Cutler \& Mehler, 1993, for Japanese; Vroomen \& de Gelder, 1995, for Dutch) all provide information on the likely locations of word boundaries. More important, there is evidence that

This research was carried out while the author was at the Max Planck Institute for Psycholinguistics in Nijmegen, The Netherlands, supported by a grant from the Max Planck Society in Munich, Germany. I thank James McQueen and Anne Cutler for their excellent advice and assistance. I also thank Rinske Goettsch for her help in the preparation of these experiments and Martin Cooper, Nicole Cooper, Peter Juszcyk, John Kingston, and three anonymous reviewers for their helpful comments on earlier versions of this paper. Correspondence concerning this article should be addressed to A. H. van der Lugt, Exeter University, Washington Singer Laboratories, Perry Road, Exeter EX4 4QG, England (e-mail: a.h.van-der-lugt@ex.ac.uk). human listeners use all of these boundary cues if they are available in the speech signal and, furthermore, that they seem to use the cues that are most effective in particular situations. If, for example, a stream of speech contains both phonotactic and metrical cues to the location of a word boundary, the adult listener will rely more strongly on the phonotactic information (McQueen, 1998). Mattys, Jusczyk, Luce, and Morgan (1999), however, found the reverse to be true for 9-month-olds. They demonstrated that infants rely more strongly on the prosodic information that is available in the speech signal.

But this is not the whole story. Segmentation can arise as a consequence of word recognition: If you know the word, you know the word boundaries. This maxim is the core assumption in two influential models of spoken word recognition: TRACE (Elman \& McClelland, 1986; McClelland, 1979, 1987, 1991; McClelland \& Elman, 1986; McClelland, \& Rumelhart, 1981) and Shortlist (Norris, 1994; Norris, McQueen, Cutler, \& Butterfield, 1997). Both models avoid explicit segmentation procedures by allowing the initial activation of multiple word candidates and the subsequent selection of the appropriate candidate from that set. Segmentation occurs as a product of this process. The models settle on an optimal parse of the input - that is, a sequence of words with boundaries between them-and achieve segmentation and recognition at the same time. In TRACE and Shortlist, the selection of the appropriate candidate is the result of competition among activated word candidates in memory. This lexical solution to the problem of segmentation can be integrated with the use of explicit boundary cues in the signal. Through the operation of the possible word constraint, candidates that are misaligned with likely boundaries are disfavored (Norris et al., 1997).

But how can you find the boundaries if you don't know the words? How does an infant, learning a language, seg- 
ment fluent speech in the absence of a lexicon of candidates that can compete for recognition? Studies in language acquisition show that, like adults, when infants listen to their native language they are sensitive to both prosodic regularities (Jusczyk, Cutler, \& Redanz, 1993; Jusczyk, Friederici, Wessels, Svenkerud, \& Jusczyk, 1993; Turk, Jusczyk, \& Gerken, 1995) and phonotactic legality constraints (Friederici \& Wessels, 1993; Jusczyk, Friederici, et al., 1993), suggesting that these cues can be exploited by the infant in the segmentation of speech.

Phonotactics constitute the extreme, categorical case of judging the familiarity of a perceived combination of sounds: Is this combination of sounds legal in this language? However, there is evidence that infants are also sensitive to more gradient transitional probabilities. Jusczyk, Luce, and Charles-Luce (1994) found that by the age of 9 months, infants prefer patterns of sounds that are relatively common in their native language over combinations of sounds that are relatively uncommon but not illegal. A recent study by Mattys et al. (1999) examined 9-month-olds' sensitivity to within- and between-word co-occurrence probabilities in speech segmentation and how this interacted with prosodic information. They demonstrated that infants prefer sequences that are very common at word junctures when the prosodic and pause information is consistent with a two-unit structure and that they prefer sequences that have a high probability of occurring inside words when this information is consistent with a single unit. Several computational demonstrations of word segmentation in acquisition (Brent \& Cartwright, 1996; Cairns, Shillcock, Chater, \& Levy, 1997; Christiansen, Allen, \& Seidenberg, 1998) have also confirmed the utility of sequential probabilities as cues to the location of word boundaries.

Sequential probabilities also affect adult speech perception. Saffran and collaborators have shown that both infants (Aslin, Saffran, \& Newport, 1998; Saffran, Aslin, \& Newport, 1996) and adults (Saffran, Newport, \& Aslin, 1996) can utilize transitional probabilities in the segmentation of an artificial language. Vitevitch, Luce, Charles-Luce, and Kemmerer (1997) found that subjects' goodness ratings of spoken nonsense words vary as a function of the sequential likelihood of the segments that they were composed of, and they replicated this finding in a speeded auditory repetition task, showing that it was easier for the subjects to repeat nonwords composed of frequent segments. Using the same repetition task, Vitevitch and Luce (1998) demonstrated that nonwords composed of phonological segments with high-probability sequential patterns are responded to more quickly and accurately than nonwords composed of phonological segments with low-probability patterns. Evidence that listeners use sequential probabilities in making phonetic decisions was found in phoneme-monitoring experiments (McQueen \& Pitt, 1996; Pitt \& Samuel, 1995) and in phonetic categorization experiments (Pitt \& McQueen, 1998). In summary, these studies show that adult listeners are sensitive to transitional probabilities, but so far no experiment has explicitly asked if and how adult lis- teners exploit these distributional cues in the segmentation of natural speech. The present experiments were designed to address exactly that question. Do adult listeners use the likelihood of a sound sequence in a certain position to direct the search for the boundaries between words?

The word-spotting task offers a way of addressing segmentation issues (e.g., McQueen, 1998; McQueen, Norris, \& Cutler, 1994; Norris, McQueen, \& Cutler, 1995; Norris et al., 1997). Experiments 1-5 all used the wordspotting task. Although uncommon diphones within a syllable or word suggest that there is a boundary between the two sounds, the likelihood of a sequence flanking the boundary should have an opposite effect, if any. If positionspecific sequential probabilities are used in parsing the speech stream, it should be easier to spot a word when it is followed (or preceded) by a sound sequence that is often the beginning (or the end) of a word or syllable. For example, it should be easier to detect boom (tree) in boomdif than in boom-douf.

The sequential probabilities that were manipulated in these experiments were all positionally specific; however, they were not specific for word boundaries. Although there may be more informative word-boundaryspecific information available to the adult listener, ${ }^{1}$ infant listeners, in the absence of a mental lexicon, are unlikely to have access to such a sophisticated segmentation cue. Furthermore, it has been shown that cues to syllable boundaries (e.g., phonotactic constraints; McQueen, 1998) can provide useful cues for possible word boundaries.

The sequence probabilities that were manipulated concerned either the likelihood that a consonant-vowel (CV) diphone was the beginning of a word or syllable or the likelihood that a vowel-consonant (VC) diphone was the end of a word or syllable. In Experiments 1-3, these likelihoods were manipulated in the context of target words. In Experiment 1, the target words could appear in both the initial (e.g., boom [tree] in boom-dif vs. boom-douf) and the final position (e.g., veer [feather] in beel-veer vs. buul-veer). Experiments 2 and 3 examined whether the observed differences in Experiment 1 were due to the intermixing of initial and final targets. Experiments 4 and 5 examined the use of similar sequential probabilities within the target words (e.g., the detection of geur in piengeur vs. the detection of galg in hien-galg). Because of the design of these last two word-spotting experiments, two lexical decision experiments (Experiments 6 and 7) were run to control for possible differences between the two different groups of target words.

\section{EXPERIMENT 1}

In Experiment 1, listeners were asked to listen to a list of bisyllabic nonsense items and to try to spot embedded words at either the beginnings or the ends of the stimuli. In Dutch, there are many words that begin with [dI], but only a few words that start with [dau]. It was hypothesized that it would be easier for a listener to detect boom (tree), for example, in boom-dif, where the Dutch target word boom is followed by the high-probability $\mathrm{CV}$ onset 
[dI], than in boom-douf, where the same target is followed by the low-probability CV onset [dau]. Similarly, many words in Dutch end with the sequence [erl], but only a few words end with the sequence [y: 1]. It was predicted that it would be easier to spot the Dutch word veer (feather) when preceded by a high-probability VC offset (e.g., veer in beel-veer) than when preceded by a lowprobability VC (e.g., veer in buul-veer).

\section{Method}

\section{General Method for Experiments 1, 2, 3, 4, and 5}

In Experiments 1-5, the same task and procedure were used, and similar general criteria for the selection of materials were adopted. The experiments differed in design, specific stimulus materials, and the identity of the subjects. In this section, all the identical features will be described.

Sequential probability criteria. Initially, all absolute frequencies of occurrence for all onset/nucleus combinations (1,048 pairs) and for all nucleus/coda combinations ${ }^{2}$ (1,390 pairs) were computed, using the phonological transcriptions in the CELEX computerized database of Dutch (Burnage, 1990). ${ }^{3}$ These sets were then restricted to all noncomplex pairs, thus yielding all the diphone combinations with a vowel in the Dutch language. For every diphone combination (383 CV pairs and $300 \mathrm{VC}$ pairs), four different absolute frequency counts were collected: the number of occurrences at the beginning $(\mathrm{CV})$ or end (VC) of a syllable in a word type and of a syllable in a word token (weighted with the word frequencies in 42 million words) and the number of occurrences at the edges (beginnings or endings) of word types and tokens. The two sets were then further restricted by including only those pairs that have a frequency larger than zero in the word type count, thus filtering out all pairs that never occur as the onset or offset of a word. The remaining $334 \mathrm{CV}$ pairs and 192 VC pairs were then consecutively ranked by all of the four frequency counts. Low-probability diphones fell in the intersection ${ }^{4}$ of the four lowest quarters of the ranked lists $(63 \mathrm{CV}$ and $40 \mathrm{VC}$ candidates); high-probability diphones fell in the intersection of the four highest quarters (39 CV and $25 \mathrm{VC}$ candidates). See Table 1 for the mean frequencies and standard deviations. ${ }^{5}$

Materials. Bisyllabic nonsense words were constructed, where either the initial syllable or the final syllable was a real word in Dutch that contained no other embedded words and where the other syllable (final or initial) was a nonword. Diphone pairs from the four probability sets were used either within the target words (Experiments 4 and 5) or in the nonsense contexts (Experiments 1-3). The target words were selected in such a way that there was a phonotactically mandatory syllable boundary between the target word and the nonsense syllable as often as possible (seven exceptions in a

Table 1

Frequency of Occurrence of the Experimental Sequences

\begin{tabular}{|c|c|c|c|c|}
\hline \multirow[b]{3}{*}{ Condition } & \multicolumn{4}{|c|}{ Sequence } \\
\hline & \multicolumn{2}{|c|}{$\mathrm{CV}$} & \multicolumn{2}{|c|}{$\mathrm{VC}$} \\
\hline & $M$ & $S D$ & $M$ & $S D$ \\
\hline \multicolumn{5}{|l|}{ Low } \\
\hline Syllable (type) & 40.7 & 39.5 & 26.1 & 29.1 \\
\hline Syllable (token) & 607.6 & 774.5 & 309.4 & 457.3 \\
\hline Word (type) & 14.0 & 13.6 & 7.5 & 7.6 \\
\hline Word (token) & 188.6 & 257.0 & 172.5 & 208.9 \\
\hline \multicolumn{5}{|l|}{ High } \\
\hline Syllable (type) & $7,573.0$ & $8,982.6$ & 7,949.9 & $9,998.7$ \\
\hline Syllable (token) & $460,687.9$ & $428,788.4$ & $555,797.4$ & $499,503.6$ \\
\hline Word (type) & $2,720.2$ & $3,209.5$ & $2,566.6$ & $3,366.2$ \\
\hline Word (token) & $314,432.9$ & $268,098.5$ & $404,040.5$ & $361,242.0$ \\
\hline
\end{tabular}

Note-Corpus size is 42 million tokens. total of 80 target-bearing bisyllables in Experiments 1-3; nine exceptions in a total of 72 target-bearing bisyllables in Experiments 4 and 5). To obtain large enough sets of materials, some target contexts were used that do not form a phonotactically illegal sequence across the syllable boundary in Dutch; in those cases, the sequence has a very low probability of occurrence within a syllable (in not more than 100 tokens in 42 million). Examples of the materials for all the experiments are given in Table 2. Sets of fillers with no embedded words were created for all the experiments.

Recording. All of the stimuli were recorded in a sound-attenuated booth. All the items were spoken three times in random order by a female native speaker of Dutch. After the recording, all the items were digitized onto a computer at a sampling frequency of $16 \mathrm{kHz}$. All the materials were measured and cut into separate speech files, using the Xwaves/ESPS speech signal-processing package. For each item, the most natural utterance was selected. The target items were inspected to make sure that all the target-bearing bisyllables were syllabified correctly between target word and nonsense syllable. The most important criterion for naturalness and syllabification was consistency across the conditions. The speech files were then transferred to the hard disk of a personal computer for use in the experiment.

Subjects. The subjects in all seven experiments were members of the subject pool of the Max Planck Institute for Psycholinguistics. None of them reported any hearing problems, and they were all native listeners of Dutch. An equal number of subjects participated in the two different versions of each experiment.

Procedure. The stimuli were presented binaurally via Sennheiser headphones. The presentation of the stimuli, the timing of the manual responses, and the collection of the data were performed by the NESU experimental control software. The subjects were tested two at a time in individual sound-attenuated booths. The subjects were instructed to listen to a series of bisyllabic nonsense words. They were asked to press a response button with their preferred hand whenever they heard a real word embedded in one of the bisyllables and to say aloud which word they had heard. Their answers were monitored on line for false alarms (trials in which they spotted a word other than an intended target word).

\section{Method for Experiment 1}

Materials. Eight CV onset+nucleus pairs, four from the high and four from the low sequential probability set, were paired with five different consonants or double consonant cluster $\mathrm{C}(\mathrm{C})$ codas to serve as following-target contexts, and similarly, four VC nucleus+ coda pairs from both sets were paired with five different $(\mathrm{C}) \mathrm{C}$ onsets to serve as preceding contexts. The consonants of the four critical diphones of the low- and high-probability sets were matched as far as possible on the identity of the consonant. In those cases in which matching was impossible, the consonants shared manner of articulation and differed only in voicing or place of articulation. This matching was necessary to make the acoustic salience of the syllable boundary as constant as possible across the two different probability conditions. The noncritical $\mathrm{VC}(\mathrm{C})$ and $(\mathrm{C}) \mathrm{CV}$ diphone pairs were all selected from within the second and third quarters of the ranked $(\mathrm{C}) \mathrm{CV}$ and $\mathrm{VC}(\mathrm{C})$ sequential probabilities; these portions of the contexts were, therefore, neither high nor low in frequency. Two sets of 80 target-bearing nonsense bisyllables were constructed, one set consisting of 40 initial CVC target words followed by 40 nonsensical CVC(C) contexts, 20 in each condition, and 40 final CVC target words preceded by 40 nonsensical (C)CVC contexts, again 20 in each condition. The two different target-context pairs for every target were counterbalanced across two different versions of the experiment, so that both versions contained a different context for each particular target word. A target word could appear only once in a single version of the experiment, combined either with a high-probability context or with a low-probability context. Each version therefore contained a total of 80 target-bearing bisyllables (40 initial and 40 final, 20 for each probability condition) and a set of 160 fillers (128 CVC-CVC, 16 CCVC-CVC, and 16 CVC-CVCC) with no em- 
Table 2

Design Materials and Examples, Experiments 1-5

\begin{tabular}{|c|c|c|}
\hline \multirow[b]{2}{*}{ Sequential Probability } & \multicolumn{2}{|c|}{ Target Position } \\
\hline & Initial & Final \\
\hline In context sequence & Experiments $1+2$ & Experiments $1+3$ \\
\hline $\begin{array}{l}\text { Low } \\
\text { High }\end{array}$ & $\begin{array}{l}\text { boom (tree) } \\
\text { in boom-douf } \\
\text { boom (tree) } \\
\text { in boom-dif }\end{array}$ & $\begin{array}{l}\text { veer (feather) } \\
\text { in buul-veer } \\
\text { veer (feather) } \\
\text { in beel-veer }\end{array}$ \\
\hline Within word sequence & Experiment 4 & Experiment 5 \\
\hline High & $\begin{array}{l}\text { heup (hip) } \\
\text { in heup-juik } \\
\text { kap (cap) } \\
\text { in kap-juif }\end{array}$ & $\begin{array}{l}\text { geur (smell) } \\
\text { in pien-geur } \\
\text { galg (gallows) } \\
\text { in hien-galg }\end{array}$ \\
\hline
\end{tabular}

bedded words. All 80 target words had a frequency in the range of 100-1,000 in 42 million tokens of the CELEX computerized database of Dutch; the items are listed in Appendix A.

Subjects. Forty subjects participated in Experiment 1.

\section{Results}

\section{Data Analysis for All Experiments}

False alarms were set to zero and treated as missing responses, as were the trials in which the subjects failed to respond entirely. Responses of duration less than $200 \mathrm{msec}$ or greater than $1,800 \mathrm{msec}$ were also treated as missing data. Reaction times (RTs) were measured from (target) word offset. The RTs and the error rates were submitted to analyses of variance (ANOVAs), with both subjects $\left(F_{1}\right)$ and items $\left(F_{2}\right)$ as the repeated measure. For the RT analyses, means were computed per condition, by subjects and by items separately, disregarding the errors.

\section{Results of Experiment 1}

As is shown in Table 3, the subjects found it harder to spot words ( $82 \mathrm{msec}$ slower) that were preceded by a probable word-final context (e.g., veer in beel-veer) than to detect words that were preceded by an improbable wordfinal context (e.g., veer in buul-veer). On the other hand, words that were followed by a very common word-initial context (e.g., boom in boom-dif) were not detected much easier ( $26 \mathrm{msec}$ faster) than words followed by a very uncommon word-initial context (e.g., boom in boom-douf). This result for final targets is the reverse of what was expected.

This pattern of results was observed in the RT analyses (14.5\% of the data treated as missing responses). There was a significant effect of boundary probability $\left[F_{1}(1,38)=6.03, M S_{\mathrm{e}}=5,028, p<.05 ; F_{2}(1,78)=\right.$ $\left.4.58, M S_{\mathrm{e}}=7,108, p<.05\right]$ and a highly significant interaction of target position and boundary probability $\left[F_{1}(1,38)=29.10, M S_{\mathrm{e}}=4,046, p<.001 ; F_{2}(1,78)=\right.$ $\left.21.09, M S_{\mathrm{e}}=7,108, p<.001\right]$. This pattern was also found in the error analyses: a significant effect of boundary probability $\left[F_{1}(1,38)=10.31, M S_{\mathrm{e}}=0.01, p<.01\right.$; $\left.F_{2}(1,78)=5.41, M S_{\mathrm{e}}=0.01, p<.05\right]$ and a significant interaction of target position and boundary probability $\left[F_{1}(1,38)=6.03, M S_{\mathrm{e}}=0.01, p<.05 ; F_{2}(1,78)=8.81\right.$, $\left.M S_{\mathrm{e}}=0.01, p<.01\right]$. Overall, the responses to targets in the high-probability conditions were slower than those in the low-probability conditions, and subjects made more errors on high-probability than on low-probability items. Since there was, in fact, an effect in the opposite direction for initial targets, these main effects of boundary probability are misleading. The interaction was inspected more closely by performing $t$ tests. Pairwise comparisons showed that the only reliable differences in RTs and errors were between the high- and the low-probability conditions for final targets [RT by subjects, $t_{1}(39)=$ $4.33, p<.001$; RT by items, $t_{2}(39)=4.26, p<.001$; errors by subjects, $t_{1}(39)=5.15, p<.001$; errors by items, $\left.t_{2}(39)=2.94, p<.01\right]$. For the initial targets, the differences between the high- and the low-probability conditions in RTs were only marginally significant [RT by subjects, $t_{1}(39)=-2.03, p<.05$; RT by items, $t_{2}(39)=-2.00$, $.05<p<.1]$. The errors were not different (both $p$ s $>.1$ ).

On average, the subjects responded $146 \mathrm{msec}$ faster to final targets than to initial targets. This effect of target position on the RTs was highly significant $\left[F_{1}(1,38)=\right.$ $92.85, M S_{\mathrm{e}}=9,154, p<.001 ; F_{2}(1,78)=30.31, M S_{\mathrm{e}}=$ $29,263, p<.001]$. This is in line with earlier findings that initial targets are harder to spot than final targets in a mixed design with both initial and final targets (McQueen et al., 1994). This pattern was repeated only partly in the error analysis: It was significant by subjects $\left[F_{1}(1,38)=17.70, M S_{\mathrm{e}}=0.01, p<.001\right]$, but not by items $\left[F_{2}(1,78)=2.47, M S_{\mathrm{e}}=0.05, p>.1\right]$.

\section{Discussion}

The observed effects do not support the initial hypothesis that it should have been easier for listeners to detect words that were followed by a very likely beginning, and they contradict the prediction that it would be easier to spot words that were preceded by a very likely ending. However, there is a potential problem with the particular task in Experiment 1. The listeners were asked to detect target words that could appear in either the initial or the final syllable of the stimuli. A possible explanation of the observed effect could be that the high-probability wordfinal contexts before the final targets were suggestive of the presence of an initial target, thus slowing down the detection of the actual finally embedded target word. This hypothesis is further supported by the error data. Listeners made almost twice as many errors in that con-

Table 3

Mean Reaction Times (in Milliseconds) and Error Rates (Percentages), Experiment 1

\begin{tabular}{|c|c|c|c|c|c|c|}
\hline \multirow{2}{*}{$\begin{array}{c}\text { Target } \\
\text { Position } \\
\end{array}$} & \multirow{2}{*}{$\begin{array}{l}\text { Sequential } \\
\text { Probability }\end{array}$} & \multicolumn{2}{|c|}{ Reaction Time } & \multicolumn{2}{|c|}{ Error Rate } & \multirow{2}{*}{$\begin{array}{c}\text { Dutch } \\
\text { Example }\end{array}$} \\
\hline & & $M$ & $S E$ & $M$ & $S E$ & \\
\hline \multirow[t]{2}{*}{ Initial } & low & 593 & 22.8 & 12.4 & 0.02 & \multirow{4}{*}{$\begin{array}{l}\text { boom (tree) } \\
\text { in boom-douf } \\
\text { boom (tree) } \\
\text { in boom-dif } \\
\text { veer (feather) } \\
\text { in buul-veer } \\
\text { veer (feather) } \\
\text { in beel-veer }\end{array}$} \\
\hline & high & 567 & 23.0 & 11.3 & 0.01 & \\
\hline \multirow[t]{2}{*}{ Final } & low & 393 & 15.9 & 12.6 & 0.01 & \\
\hline & high & 475 & 21.6 & 21.9 & 0.02 & \\
\hline
\end{tabular}


dition as in the other three conditions. The highly probable VC sequences activate many lexical candidates in the initial position. These candidates all compete with each other for recognition but are more suggestive of an initial target than are the fewer lexical candidates activated by the lower probability VC sequences. Detection of the final target is thus delayed in the high-probability condition. This explanation is in line with findings by Luce et al. on the role of similarity neighborhood frequencies 6 in spoken word recognition (e.g., Cluff \& Luce, 1990; Goldinger, Luce, \& Pisoni, 1989; Luce \& Pisoni, 1998; Luce, Pisoni, \& Goldinger, 1990). Furthermore, Vitevitch and Luce $(1998,1999)$ have shown that, depending on the nature of the processing environment and the task demands, sequential probability manipulations can have opposite effects on word recognition performance: inhibitory lexical competition effects and facilitatory sequential probability effects. The finding that high-probability contexts made detection of final targets harder could thus be a lexical competition effect, one that was emphasized by task-level competition between initial and final targets.

The absence of such a competition effect for initial targets can be explained by the sequential nature of spoken word recognition: The later incoming information of the following-target context is too late to interfere with the detection of the initial target. The effects of the followingtarget context on word-spotting performance have been shown to be weak (McQueen, 1998) or even absent (Suomi et al., 1997).

To explore these issues, two experiments were carried out with subsets of the materials in Experiment 1. In these experiments, the subjects monitored for target words in only one position. In a series of word-spotting experiments, McQueen et al. (1994) have shown that blocked target location can attenuate lexical effects. It was therefore predicted that if the listener could attend to a single location, the beginning or the end of a nonsense bisyllable, responselevel competition with lexical candidates in the other position would decrease. The subjects were asked to listen only for initially embedded words in Experiment 2 and only for finally embedded words in Experiment 3.

\section{EXPERIMENT 2}

\section{Method}

Materials. All 80 initial target-bearing nonsense bisyllables from Experiment 1 were mixed with 80 appropriate fillers. Again, the two different target-context pairs for every target were counterbalanced across two different versions of the experiment, so that both versions contained a different context for each particular target word. Each version therefore contained a total of 40 initial targetbearing bisyllables ( 20 for each probability condition) and a set of 80 fillers (64 CVC- CVC, 16 CVC-CVCC) with no embedded words.

Subjects. Forty subjects participated in Experiment 2.

\section{Results and Discussion}

The subjects were, on average, $25 \mathrm{msec}$ faster in spotting targets that were followed by a high-probability boundary CV (see Table 4). This difference, however, was not completely reliable. The analyses of RTs $(6.4 \%$ of the data
Table 4

Mean Reaction Times (in Milliseconds) and Error Rates (Percentages), Experiments 2 and 3

\begin{tabular}{|c|c|c|c|c|c|c|}
\hline \multirow{2}{*}{$\begin{array}{c}\text { Target } \\
\text { Position }\end{array}$} & \multirow{2}{*}{$\begin{array}{l}\text { Sequential } \\
\text { Probability }\end{array}$} & \multicolumn{2}{|c|}{$\underline{\text { Reaction Time }}$} & \multicolumn{2}{|c|}{$\underline{\text { Error Rate }}$} & \multirow{2}{*}{$\begin{array}{c}\text { Dutch } \\
\text { Example }\end{array}$} \\
\hline & & $M$ & $S E$ & $M$ & $S E$ & \\
\hline \multicolumn{7}{|c|}{ Experiment 2} \\
\hline \multirow[t]{2}{*}{ Initial } & low & 506 & 22.8 & 6.6 & 0.01 & \multirow{2}{*}{$\begin{array}{l}\text { boom (tree) } \\
\text { in boom-douf } \\
\text { boom (tree) } \\
\text { in boom-dif }\end{array}$} \\
\hline & high & 481 & 24.4 & 6.1 & 0.01 & \\
\hline \multicolumn{7}{|c|}{ Experiment 3} \\
\hline \multirow[t]{2}{*}{ Final } & low & 363 & 17.6 & 8.9 & 0.01 & \multirow{2}{*}{$\begin{array}{l}\text { veer (feather) } \\
\text { in buul-veer } \\
\text { veer (feather) } \\
\text { in beel-veer }\end{array}$} \\
\hline & high & 373 & 18.5 & 8.3 & 0.01 & \\
\hline
\end{tabular}

discarded) revealed a significant effect of boundary probability in the subjects analysis $\left[F_{1}(1,38)=7.29, M S_{\mathrm{e}}=\right.$ $1,728, p<.05]$, but this effect did not reach significance in the items analysis $\left[F_{2}(1,78)=1.88, M S_{\mathrm{e}}=5,292, p>\right.$ .1]. No reliable differences in listeners' performance were found in the error analyses.

The results of Experiment 2 are in line with the results for the initial targets of Experiment 1. Listeners responded faster to words that were followed by a very likely word onset sequence, but not reliably so. No differences were found in the error rates. Although these results are suggestive of the predicted facilitatory effect of a common following-target context, they do not provide strong evidence that position-specific sequential probabilities are used by the listener in this situation.

\section{EXPERIMENT 3}

\section{Method}

Materials. The 80 final target-bearing nonsense bisyllables from Experiment 1 were combined with 80 appropriate fillers in two different versions. The design was identical to that in Experiment 2.

Subjects. Forty subjects participated in Experiment 3.

\section{Results and Discussion}

The subjects were, on average, $10 \mathrm{msec}$ faster in detecting embedded words that were preceded by a lowprobability boundary VC (see Table 4 ). This difference, however, was not statistically reliable. Both in RTs $(8.6 \%$ missing responses) and in error rates, no reliable differences $(p>.1)$ were found between the two probability conditions.

In Experiment 1, in which the subjects were asked to listen for words that were embedded either at the beginnings or at the ends of the bisyllabic nonsense items, it was harder for listeners to detect words that were preceded by a probable word-final context than to detect words that were preceded by an improbable word-final context. In the present experiment, the subjects were monitoring exclusively for final embedded words in a set of materials that did not contain any initial embedded words. Under these circumstances, it was equally hard to detect a target in a common preceding context as in an uncommon pre- 
ceding context. This is in line with the prediction that the attentional focus on a single location (i.e., the end of the stimulus) would diminish the effects of competition with candidates in the other location (i.e., the beginning of the stimulus).

Nevertheless, no actual reversal of the lexical competition effect was observed. This is not surprising. To a large extent, competition is an automatic feature of spoken word recognition (see also McQueen et al., 1994). The highprobability sequences still will have activated many lexical candidates, causing a weaker competition effect, even when the possibility of embedded words in the initial position was not emphasized by the task or the materials. This lexical competition effect still may have canceled out any facilitatory segmentation effect of sequential probability. A second series of experiments was therefore planned in which sequential likelihoods were manipulated within the embedded words. In order to avoid effects that could be caused by the intermixing of initial and final targets, these effects were investigated in two separate word-spotting experiments with initial and final embeddings, respectively.

\section{EXPERIMENT 4}

In Experiment 4, listeners were asked to listen for embedded words at the beginnings of bisyllabic nonsense items. Hearing a combination of sounds that often occurs immediately before a syllable or word boundary (e.g., [ap] in Dutch) may facilitate recognition of a target word that ends with that combination of sounds. Conversely, hearing a combination of sounds that seldom occurs as the end of a syllable or word (e.g., [ø:p] in Dutch) may interfere with the recognition of a word that ends with that sequence. It was hypothesized that it would be easier to detect kap (cap) in kap-juif than to detect heup (hip) in heup-juik.

\section{Method}

Materials. A slightly different procedure was used for the construction of materials from the sets of CV and VC segments. First, a list was generated that consisted of all the monosyllabic words of Dutch that end in one of the VC nucleus+coda pairs from the low sequential probability set. Second, a similar list was constructed for the high-probability set. The words from these lists were matched on their syllabic structure, the manner of articulation of the final consonant, and as far as possible, on the place of articulation of the final consonant. The two sets of words were also matched, as far as possible, on the frequencies of occurrence of the words in the CELEX database and on the variance of these frequencies. ${ }^{7}$ This resulted in two sets of 15 words, $9 \mathrm{CCVC}$ and $6 \mathrm{CVC}$, with a mean log frequency of $2.14(S D=0.50)$ for the high-probability set and a mean log frequency of $2.16(S D=0.49)$ for the low-probability set. Two sets of 15 nonsense syllables without embedded words were constructed, using $15 \mathrm{CV}$ segments with normal positional segment probabilities (i.e., segments selected from within the second and third quarters of the ranked $\mathrm{CV}$ and $\mathrm{VC}$ sequential probability lists), that were all paired with two different coda consonants (see also Table 2). These 15 pairs of nonsense syllables were placed in the final context of the target words in such a way that the two target words that were matched on their final consonant were combined with a context that started with the same CV segment. The experiment therefore con- tained a total of 30 target-bearing bisyllables (15 for each probability condition) and a set of 60 fillers (24 CVC-CVC and 36 CCVC$\mathrm{CVC}$ ) with no embedded words. The target-bearing items are listed in Appendix B.

Subjects. Twenty-one subjects participated in Experiment 4.

\section{Results and Discussion}

The results suggest that it is easier to detect words with a common VC offset. The listeners were faster and made fewer mistakes when the embedded words ended with a very likely sequence (such as [ap] rather than [ø: p]).

The subjects were, on average, $49 \mathrm{msec}$ faster in spotting targets that ended in a high-probability boundary VC (see Table 5). The RT analyses ( $12.4 \%$ missing) revealed a significant effect of boundary probability in the subjects analysis $\left[F_{1}(1,21)=5.77, M S_{\mathrm{e}}=4,397, p<\right.$ $.05]$, but not in the items analysis $\left[F_{2}(1,28)=2.87\right.$, $\left.M S_{\mathrm{e}}=13,090, p>.1\right]$. In the analysis of the errors, more reliable differences in listeners' performance were found between the probability conditions. The listeners made, on average, $14 \%$ more errors in spotting targets that ended in a low-probability boundary VC. This effect was significant both by subjects $\left[F_{1}(1,21)=48.58, M S_{\mathrm{e}}=0.001\right.$, $p<.01]$ and by items $\left[F_{2}(1,28)=7.00, M S_{\mathrm{e}}=0.02, p<.05\right]$.

Because different items were used in the two probability conditions, additional analyses were performed for Experiments 4-7 to investigate possible effects of the specific items that were used. Correlation analyses and analyses of covariance (ANCOVAs) are reported for target duration and/or target frequency only if those differences indeed had an effect (as revealed by a significant correlation).

Although an attempt was made to control for differences in target frequency and variation, targets in the high-probability set had, on average, a slightly smaller log frequency than did the words in the low-probability set. A significant negative correlation of target log frequency and RT was found $[r(30)=-.41, p<.05]$. An ANCOVA with target frequency as covariate showed that the effect of probability was more reliable than was shown in the items ANOVA, but it remained only marginally significant $\left[F_{2}(1,27)=3.67, M S_{\mathrm{e}}=11,005, p<.1\right]$. The correlation between target duration and RT was not reliable.

Table 5

Mean Reaction Times (in Milliseconds) and Error Rates (Percentages), Experiments 4 and 5

\begin{tabular}{|c|c|c|c|c|c|c|}
\hline \multirow{2}{*}{$\begin{array}{c}\text { Target } \\
\text { Position }\end{array}$} & \multirow{2}{*}{$\begin{array}{l}\text { Sequential } \\
\text { Probability }\end{array}$} & \multicolumn{2}{|c|}{ Reaction Time } & \multicolumn{2}{|c|}{ Error Rate } & \multirow{2}{*}{$\begin{array}{c}\text { Dutch } \\
\text { Example }\end{array}$} \\
\hline & & $M$ & $S E$ & $M$ & $S E$ & \\
\hline \multicolumn{7}{|c|}{ Experiment 4} \\
\hline \multirow[t]{2}{*}{ Initial } & low & 669 & 46.7 & 19.7 & 0.02 & \multirow{2}{*}{$\begin{array}{l}\text { heup (hip) } \\
\text { in heup-juik } \\
\text { kap (cap) } \\
\text { in kap-juif }\end{array}$} \\
\hline & high & 620 & 32.1 & 5.2 & 0.01 & \\
\hline \multicolumn{7}{|c|}{ Experiment 5} \\
\hline \multirow[t]{2}{*}{ Final } & low & 492 & 29.8 & 8.9 & 0.02 & \multirow{2}{*}{$\begin{array}{l}\text { geur (smell) } \\
\text { in pien-geur } \\
\text { galg (gallows) } \\
\text { in hien-galg }\end{array}$} \\
\hline & high & 444 & 22.4 & 7.4 & 0.02 & \\
\hline
\end{tabular}




\section{EXPERIMENT 5}

In Experiment 5, the listeners were asked to listen exclusively for embedded words at the ends of bisyllabic nonsense items. Hearing a combination of sounds that often occurs immediately after a syllable or word boundary-for instance, [xa] in Dutch-may facilitate recognition of a target word that begins with that combination of sounds; hearing a combination of sounds that seldom occurs as the beginning of a syllable or word-for example, [xø:] in Dutch-may interfere with the recognition of a word that begins with that sequence. It was hypothesized that it would be harder to spot geur (smell) in pien-geur than to spot galg (gallows) in hien-galg.

\section{Method}

Materials. The materials for this experiment were constructed in a similar way to those in Experiment 4. This resulted in two sets of 21 words, $4 \mathrm{CVCC}$ and $17 \mathrm{CVC}$, with a mean $\log$ frequency of 2.30 $(S D=0.56)$ for the high-probability set and a mean $\log$ frequency of $2.28(S D=0.54)$ for the low-probability set. Two sets of 21 nonsense syllables without embedded words were constructed, using $21 \mathrm{VC}$ segments with normal positional segment probabilities, that were all paired with two different onset consonants. These 21 pairs of nonsense syllables were placed in the initial context of the target words in such a way that the two target words that were matched on their initial consonant were combined with a context that ended with the same VC segment (see also Table 2). The experiment therefore contained a total of 42 target-bearing bisyllables ( 21 for each probability condition) and a set of 84 fillers (16 CVC-CVCC and $68 \mathrm{CVC}$ $\mathrm{CVC}$ ) with no words embedded in them. The target-bearing items are listed in Appendix B.

Subjects. Twenty-one subjects participated in Experiment 5.

\section{Results}

The subjects were, on average, $48 \mathrm{msec}$ faster in spotting targets that started with a high-probability boundary CV (see Table 5). The RT analyses ( $8.1 \%$ missing values) revealed a highly significant effect of boundary probability by subjects $\left[F_{1}(1,21)=10.58, M S_{\mathrm{e}}=2,357\right.$, $p<.01]$, but not by items $\left[F_{2}(1,40)=1.90, M S_{\mathrm{e}}=12,145\right.$, $p>.1]$. The listeners made just as many errors in spotting targets that began with a common $\mathrm{CV}$ as in spotting targets with an uncommon $\mathrm{CV}$ onset $\left(F_{1}\right.$ and $F_{2}$, n.s.).

Targets in the high-probability set were shorter than targets in the low-probability set (low probability, $497 \mathrm{msec}$; high probability, $454 \mathrm{msec}$ ), and the targets in the highprobability set had, on average, a slightly higher log frequency than did the words in the low-probability set. Further analyses showed a significant negative correlation of target duration and RT $[r(42)=-.42, p<.01]$ and a significant negative correlation of target frequency and RT $[r(42)=-.41, p<.01]$.

\section{Discussion}

These findings are consistent with results from previous word-spotting studies. Subjects have been shown to respond faster to longer embedded targets (McQueen, 1998). The present results, however, cannot be explained by durational differences between the two probability conditions. In fact, the target duration effect is working against the sequential probability effect, since the items in the high-probability set were shorter than those in the lowprobability set. It has also been shown that listeners are faster and more accurate in detecting high-frequency than low-frequency words (Freedman, 1992). In the present study, the items from the high-probability set were slightly more frequent than the items from the low-probability set. Thus, part of the processing advantage for high-probability items might be explained by this difference in frequency. Frequency and duration were therefore both entered as covariates in an ANCOVA of the RTs by items. The effect of probability was now significant $\left[F_{2}(1,38)=6.63\right.$, $\left.M S_{\mathrm{e}}=8,207, p<.05\right]$. This suggests that differences in duration and frequency between the high-probability and the low-probability items were partly neutralizing the effect of positional probability. Similar analyses were performed for the errors. Both duration $[r(42)=-.51, p<$ $.01]$ and frequency $[r(42)=-.49, p<.01]$ were significantly correlated with the error rates. An ANCOVA showed no significant differences between the two probability conditions.

These results suggest that the faster detection latencies for words that began with a common CV onset cannot be explained by durational differences or frequency differences between the high- and the low-probability sets. But since different targets were used in these two probability sets, it was necessary to make a closer examination of the possibility that differences other than the probability of the initial CV segments between the two sets were responsible for this effect. As control experiments, lexical decision experiments were used to investigate the possibility that differences other than the segment probabilities of the target words made it easier to spot words that ended (Experiment 4) or started (Experiment 5) with common segments. In order to keep the experiments as closely related as possible to the earlier experiments, separate control experiments were carried out for the embedded words from Experiments 4 and 5.

\section{EXPERIMENT 6}

If the different effects for the low- versus the highprobability target words from the word-spotting experiments are due to the relative ease of segmentation that is caused by the manipulated probabilistic cues to the location of the syllable boundary, these differences should not be found if the target words are presented in isolation. It is assumed that when monosyllabic words and nonwords are presented in isolation - that is, when the beginnings and ends of the words are unambiguously cued by silence-no effects of sequential probability will arise, because there is no need for segmentation in this situation. But if the relative ease of spotting targets from the high-probability set was caused by some other difference that was not directly related to the ease of segmentation (e.g., an acoustic difference between the items in the highand the low-probability sets), the same pattern of results should be found in the lexical decision task. 
In Experiment 6, all of the initially embedded target words from Experiment 4 were cut out from the original bisyllabic nonsense items. Nonsense monosyllables were constructed by cutting out the first syllables from the Experiment 4 bisyllabic fillers. All the items were presented to the listener in the same order as that used in Experiment 4 , and they were asked to respond only when they heard a real word by pressing the response button and to say aloud the real word that they heard. This go/no-go lexical decision task is a fairly standard control for wordspotting experiments (McQueen, 1996).

\section{Method}

Materials. The items were all constructed from the items that were used in Experiment 4. Target words were constructed by excising the first syllables from the target-bearing bisyllables; the first syllables from the original filler items were cut out to serve as nonword fillers. The items were excised at zero-crossings on the basis of visual and auditory inspection of the waveform, under the constraint that this point was consistent across the two probability conditions. For this purpose, the Xwaves speech editor was used. The order of presentation was the same as that in Experiment 4.

Subjects and Procedure. Twenty-four subjects participated. Subjects that had already participated in Experiment 4 or 5 were excluded. The procedure was similar to the procedure used in the word-spotting experiments. The only difference was that the subjects were now instructed to respond whenever they heard a real word. As before, the subjects were asked to name the word they recognized after the manual response.

\section{Results and Discussion}

The listeners were, on average, $23 \mathrm{msec}$ faster in detecting targets that ended in a high-probability boundary $\mathrm{VC}$ (see Table 6), but this difference was not significant (12.8\% missing; both $p$ s $>.1)$. In the analysis of the errors, a more reliable difference was found in the listeners' performance. Listeners made $10 \%$ more errors in detecting targets that ended in a low-probability boundary VC. This effect was highly significant by subjects $\left[F_{1}(1,23)=\right.$ $\left.30.19, M S_{\mathrm{e}}<0.01, p<.001\right]$ and marginally significant by items $\left[F_{2}(1,28)=3.65, M S_{\mathrm{e}}=0.02, p>.05\right]$.

Additional correlation analyses were performed in order to quantify the relationship between these results and the word-spotting results. Lexical decision and word-spotting latencies were highly correlated $[r(30)=$ $.60, p<.001]$, and the error rates also showed a robust correlation $[r(30)=.64, p<.001]$. As a final control, the RT data and the error data from the lexical decision experiment were entered as covariates in ANCOVAs of the word-spotting responses of Experiment 4 . These analyses showed that when the effects of the specific target items used were filtered out, no reliable differences were left between the detection of embedded words that ended with a likely VC offset and the detection of embedded words that ended with an unlikely VC offset $\left[\mathrm{RTs}, F_{2}(1,27)\right.$ $=2.30, M S_{\mathrm{e}}=8,797, p>.1$; errors, $F_{2}(1,27)=3.04$, $\left.M S_{\mathrm{e}}=0.02, p>.05\right]$.

\section{EXPERIMENT 7}

In Experiment 7, all of the finally embedded target words from Experiment 5 were cut out from the original bisyllabic nonsense items. Nonsense monosyllables were constructed by cutting out the second syllables from the Experiment 5 fillers.

\section{Method}

Materials. The items were all constructed from the items that were used in Experiment 5, in the same way as in Experiment 6.

Subjects and Procedure. Twenty-four subjects participated. Subjects that had already participated in Experiment 4, 5, or 6 were excluded. The procedure was the same as that in Experiment 6 .

\section{Results and Discussion}

The listeners were, on average, $24 \mathrm{msec}$ slower in detecting words that started with a high-probability boundary CV (see Table 6). This difference was not significant $\left(F_{1}\right.$ and $\left.F_{2}, p>.1\right)$. The subjects never recognized words other than the intended targets, but the error rate was much higher than in the original word-spotting experiment $(25.2 \%$ vs. $8.1 \%)$. There is a simple acoustic explanation for this increase in errors. Because the finally embedded target words were excised from their original context, many of the beginnings of the items were not very clear, owing to residual coarticulatory information from

Table 6

Mean Reaction Times (in Milliseconds) and Error Rates (Percentages), Experiments 6 and 7

\begin{tabular}{|c|c|c|c|c|c|c|}
\hline \multirow{2}{*}{$\begin{array}{c}\text { Target } \\
\text { Position }\end{array}$} & \multirow{2}{*}{$\begin{array}{l}\text { Sequential } \\
\text { Probability }\end{array}$} & \multicolumn{2}{|c|}{ Reaction Time } & \multicolumn{2}{|c|}{ Error Rate } & \multirow[b]{2}{*}{ Dutch Example } \\
\hline & & $M$ & $S E$ & $M$ & $S E$ & \\
\hline \multicolumn{7}{|c|}{ Experiment 6} \\
\hline \multirow[t]{2}{*}{ Initial } & low & 506 & 22.4 & 18.1 & 0.02 & \multirow{2}{*}{$\begin{array}{l}\text { heup (hip) } \\
\text { excised from heup-juik } \\
\text { kap (cap) } \\
\text { excised from kap-juif }\end{array}$} \\
\hline & high & 483 & 25.2 & 7.5 & 0.02 & \\
\hline \multirow{3}{*}{ Final } & & & Experi & nent 7 & & \multirow{3}{*}{$\begin{array}{l}\text { geur (smell) } \\
\text { excised from pien-geur } \\
\text { galg (gallows) } \\
\text { excised from hien-galg }\end{array}$} \\
\hline & low & 463 & 24.6 & 24.2 & 0.03 & \\
\hline & high & 487 & 19.9 & 26.2 & 0.03 & \\
\hline
\end{tabular}


the offset of the first syllable. However, this affected the items in both probability sets equally. In the analysis of the errors also, no reliable differences were found (both $p \mathrm{~s}>.1$ ).

Lexical decision and word-spotting latencies were again highly correlated $[r(42)=.63, p<.001]$, and the error rates from both tasks again showed a robust correlation $[r(42)=.51, p<.001]$. The ANCOVA of the wordspotting errors, with the lexical decision errors as covariate, yielded no reliable differences between the two probability conditions. The ANCOVA of the word-spotting RTs, with the lexical decision RTs as covariate, confirmed the earlier findings that it was easier for the listener to detect words that began with a common onset than words that began with an uncommon onset $\left[F_{2}(1,39)=5.33\right.$, $\left.M S_{\mathrm{e}}=6,964, p<.05\right]$. It is therefore unlikely that the observed effect for the common onsets in Experiment 5 was due to the use of particular target items in the two probability sets.

\section{GENERAL DISCUSSION}

In these experiments, the influence of sequential probabilities on the segmentation of speech has been systematically examined. In Experiment 1 and the control Experiments 2 and 3 , it was demonstrated that the listeners' sensitivity to sequential likelihoods could be obscured by higher order effects, owing to competition between lexical candidates. When targets could occur in both initial and final positions (Experiment 1), the sequences of segments in the context activated lexical candidates to the extent that they interfered with detection of the intended target word. In line with McQueen et al. (1994, Experiment 2), this competition effect was shown to be in part task specific. In Experiments 2 and 3, in which target words occurred in a single position, the lexical competition effect was no longer observed. This is also consistent with the results of recent studies by Vitevitch and Luce $(1998,1999)$. They demonstrated that the processing of speech is a function of both facilitatory effects associated with sequential probabilities and inhibitory effects associated with lexical competitors. In particular, they showed that the task environment can differentially emphasize lexical and sublexical levels of processing.

In the second series of experiments, sequential probability was manipulated within the target words. The results of Experiments 4 and 6 provide no reliable support for the hypothesis that listeners use the likelihood of a word's offset as a boundary cue when this boundary is also marked by a phonotactically mandatory boundary. Experiment 5 and the control lexical decision Experiment 7, however, demonstrated that the listener can exploit the likelihood of a word's onset in combination with a phonotactic boundary in the segmentation of speech. Common sequences at the onset of a word made it easier for the listeners to detect these words in a word-spotting task; however, they did not affect performance in the lexical decision task. These findings provide converging evidence that sublexical levels of processing operate in the recognition of spoken stimuli, even for words. In line with previous research (Vitevitch \& Luce, 1999), it has been demonstrated that sublexical sequential probability effects manifest themselves when effects of lexical competition are minimized. In Experiments 4 and 5 of the present study, this was established by manipulating sequential probabilities within the target words and by blocking target position.

The likelihood of a word's onset seems to be more important than the likelihood of a word's offset. Many studies have confirmed the intuitive notion that the beginnings of words are particularly important for the fast recognition of words in continuous speech. Gating studies (Grosjean, 1980; Tyler \& Wessels, 1983, 1985) have shown that words can be recognized reliably before their offset, at the point at which they become unique with respect to all other words in the language (the uniqueness point). Other evidence from phoneme monitoring (MarslenWilson, 1984), auditory lexical decision (Taft, 1986), mispronunciation detection(Cole, 1973; Marslen-Wilson $\&$ Welsh, 1978), and cross-modal priming (MarslenWilson, 1987; Marslen-Wilson \& Zwitserlood, 1989; Zwitserlood, 1989) also suggests that word-initial information is crucial for efficient word recognition. In the present study, there is a confound between increases in word-spotting latency and the position of the target word. The RTs for initial target words in Experiment 4 were much longer than the RTs for final targets in Experiment 5. Two issues are relevant with respect to this difference. First, statistical power may have been reduced by the higher variance associated with longer RTs. Second, if effects of sequential probability are short-lived, one might argue that the subjects responded too late for probability effects to be observed. Therefore, no strong conclusions on the positional specificity of the sequential probability effect can be drawn on the basis of these results.

In Experiments 4 and 5, words with high-probability sequences by definition come from a high-density similarity neighborhood. Similarly, words with low-probability sequences come from a low-density neighborhood.Therefore, the findings in Experiments 6 and 7 could be interpreted as a failure to replicate the results of Luce and Pisoni (1998), whose neighborhood activation model predicts that words in dense lexical neighborhoods should take longer to recognize than words in sparse neighborhoods. However, as was also shown by Vitevitch and Luce (1999, Experiment 2), lexical effects can be substantially attenuated by the task demands and processing environment. In the present experiments, this attenuation of lexical effects was most likely due to the fact that the words were excised from a bisyllabic context.

These findings provide further evidence that listeners have access to information regarding the probability that a particular sequence of phonemes occurs at a certain position within a syllable or word. More important, the results also show that listeners exploit this kind of information in the segmentation of words from longer sequences. Current implementations of models of spoken word recognition - for instance, the Shortlist model (Nor- 
ris et al., 1997)—lack a mechanism to account for these findings. Such a mechanism would incorporate some kind of prelexical analysis of the speech signal that would result in the accumulation and storage of distributional information. A different approach is taken by Vitevitch and Luce (1999). In recent work, they proposed an adaptive resonance framework (Grossberg, Boardman, \& Cohen, 1997) to account for both the lexical and the sublexical levels of the processing of speech. In this approach, the two levels of processing are modeled by a single mechanism (rather than by a prelexical and a lexical mechanism). Resonant states between chunks in shortterm memory and items in working memory constitute the speech percept. If sublexical chunks (corresponding to units smaller than words) in short-term memory are the most predictive (for instance, in the case of a nonword input), the model reflects sublexical processing. If lexical chunks are consistent with the item in working memory (for instance, when the input is a word), they will dominate processing, since they represent a larger stretch of the input. In this case, the model reflects a lexical level of processing (see also Vitevitch \& Luce, 1999).

A final point to note about these results is that the use of sequential probability information as a cue to segmentation has been investigated only in conjunction with one other cue to the location of word boundaries-namely, those that are marked by phonotactics. The different findings for adults (McQueen, 1998) and infants (Mattys et al., 1999) on the integration of prosodic and phonotactic boundary markers show that the operation of an explicit boundary cue can vary enormously, depending on the situation. Future research should therefore include experiments on the interaction of sequential probability information before and after the boundary, the interaction with other boundary cues, and the use of sequential probability cues in the absence of other explicit boundary cues.

In summary, two limitations were observed in the use of sequential probabilities as a cue for segmentation. The probability of a sound sequence influenced segmentation more when the sequence occurred within the target words (Experiments 4-7 vs. Experiments 1-3). Furthermore, the effects were stronger when the sequences occurred in onset position (Experiments 1, 2, 5, and 7 vs. Experiments 1, 3, 4, and 6). It has been argued that these limitations may only be artifacts that are introduced by the task environment and, therefore, the issue of whether these are genuine limitations of the use of sequential probabilities in segmentation is still unresolved. Nevertheless, at least in these conditions, position-specific sequential probabilities appear to be used to direct the segmentation of speech by adult listeners.

\section{REFERENCES}

Aslin, R. N., Saffran, J. R., \& Newport, E. L. (1998). Computation of conditional probability statistics by 8 -month-old infants. Psychological Science, 9, 321-324.
BoolJ, G. (1995). The phonology of Dutch. Oxford: Oxford University Press, Clarendon Press.

Brent, M. R., \& CARtwright, T. A. (1996). Distributional regularity and phonotactic constraints are useful for segmentation. Cognition, 61, 93-125.

Burnage, G. (1990). CELEX: A guide for users. Nijmegen: University of Nijmegen.

Cairns, P., Shillcock, R., Chater, N., \& Levy, J. (1997). Bootstrapping word boundaries: A bottom-up corpus-based approach to speech segmentation. Cognitive Psychology, 33, 111-153.

Christiansen, M. H., Allen, J., \& Seidenberg, M. S. (1998). Learning to segment speech using multiple cues: A connectionist model. Language \& Cognitive Processes, 13, 221-268.

Cluff, M., \& Luce, P. A. (1990). Similarity neighborhoods of spoken two-syllable words: Retroactive effects on multiple activation. Journal of Experimental Psychology: Human Perception \& Performance, 16, 551-563.

Cole, R. A. (1973). Listening for mispronunciations: A measure of what we hear during speech. Perception \& Psychophysics, 13, 153-156.

Cutler, A., Mehler, J., Norris, D., \& Segui, J. (1986). The syllable's differing role in the segmentation of French and English. Journal of Memory \& Language, 25, 385-400.

CUtler, A., \& Norris, D. (1988). The role of strong syllables in segmentation for lexical access. Journal of Experimental Psychology: Human Perception \& Performance, 14, 113-121.

Elman, J. L., \& McClelland, J. L. (1986). Cognitive penetration of the mechanisms of perception: Compensation for coarticulation of lexically restored phonemes. Journal of Memory \& Language, 27, 143 165.

Freedman, D. (1992). Frequency effects in auditory word recognition using the word-spotting task. Unpublished undergraduate project, University of Cambridge, Department of Experimental Psychology.

Friederici, A. D., \& Wessels, J. M. I. (1993). Phonotactic knowledge of word boundaries and its use in infant speech perception. Perception \& Psychophysics, 54, 287-295.

Goldinger, S. D., Luce P. A., \& Pisoni, D. B. (1989). Priming lexical neighbors of spoken words: Effects of competition and inhibition. Journal of Memory \& Language, 28, 501-518.

Gow, D. W., \& Gordon, P. C. (1995). Lexical and prelexical influences on word segmentation: Evidence from priming. Journal of Experimental Psychology: Human Perception \& Performance, 21, 344-359.

Grosjean, F. (1980). Spoken word recognition processes and the gating paradigm. Perception \& Psychophysics, 28, 267-283.

Grossberg, S., Boardman, I., \& Cohen, M. (1997). Neural dynamics of variable speech rate categorization. Journal of Experimental Psychology: Human Perception \& Performance, 23, 483-503.

Jusczy K, P. W., Cutler, A., \& Redanz, N. J. (1993). Infant's preference for the predominant stress patterns of English words. Child Development, 64, 675-687.

Jusczyk, P. W., Friederici, A. D., Wessels, J., Svenkerud, V. Y., \& JUSCZYK, A. M. (1993). Infants' sensitivity to the sound patterns of native language words. Journal of Memory \& Language, 32, 404-420.

Jusczy K, P. W., Luce, P. A., \& Charles-Luce, J. (1994). Infants' sensitivity to phonotactic patterns in the native language. Journal of Memory \& Language, 33, 630-645.

KLATT, D. H. (1976). Linguistic uses of segmental duration in English: Acoustic and perceptual evidence. Journal of the Acoustical Society of America, 59, 1208-1221.

LEHISTE, I. (1972). The timing of utterances and linguistic boundaries. Journal of the Acoustical Society of America, 51, 2018-2024.

Luce, P. A., \& Pisoni, D. B. (1998). Recognizing spoken words: The neighborhood activation model. Ear \& Hearing, 19, 1-36.

Luce, P. A., Pisoni, D. B., \& Goldinger, S. D. (1990). Similarity neighborhoods of spoken words. In G. T. M. Altmann (Ed.), Cognitive models of speech processing: Psycholinguistic and computational perspectives (pp. 122-147). Cambridge, MA: MIT Press.

Marslen-Wilson, W. D. (1984). Function and process in spoken word recognition. In H. Bouma \& D. G. Bouwhuis (Eds.), Attention and performance X: Control of language processes (pp. 125-150). Hillsdale, NJ: Erlbaum. 
MarsLen-Wilson, W. D. (1987). Functional parallelism in spoken word recognition. Cognition, 25, 71-102.

Marslen-Wilson, W. D., \& Welsh, A. (1978). Processing interactions and lexical access during word recognition in continuous speech. Cognitive Psychology, 10, 29-63.

Marslen-Wilson, W. D., \& Zwitserlood, P. (1989). Accessing spoken words: The importance of word onsets. Journal of Experimental Psychology: Human Perception \& Performance, 15, 576-585.

Mattys, S. L., Jusczy K P. W., Luce, P. A., \& Morgan, J. L. (1999). Word segmentation in infants: How phonotactics and prosody combine. Cognitive Psychology, 38, 465-494.

McClelland, J. L. (1979). On the time relations of mental processes: An examination of systems of processes in cascade. Psychological Review, 86, 287-330.

McClelland, J. L. (1987). The case for interactionism in language processing. In M. Coltheart (Ed.), Attention and performance XII: The psychology of reading (pp. 3-35). Hillsdale, NJ: Erlbaum.

McClelland, J. L. (1991). Stochastic interactive processes and the effect of context on perception. Cognitive Psychology, 23, 1-44.

McClelland, J. L., \& Elman, J. L. (1986). The TRACE model of speech perception. Cognitive Psychology, 18, 1-86.

McClelland, J. L., \& Rumelhart, D. E. (1981). An interactive activation model of context effects in letter perception: 1 . An account of basic findings. Psychological Review, 88, 375-407.

McQueen, J. M. (1996). Word spotting. Language \& Cognitive Processes, 11, 695-699.

McQueen, J. M. (1998). Segmentation of continuous speech using phonotactics. Journal of Memory \& Language, 39, 21-46.

McQueen, J. M., Norris, D., \& Cutler, A. (1994). Competition in spoken word recognition: Spotting words in other words. Journal of Experimental Psychology: Learning, Memory, \& Cognition, 20, 621-638.

McQueen, J. M., \& PitT, M. A. (1996). Transitional probabilities and phoneme monitoring. In H. T. Bunnell \& W. Idsardi (Eds.), Proceedings of the Fourth International Conference on Spoken Language Processing (Vol. 4, pp. 2502-2505). Wilmington: University of Delaware and Alfred I. Dupont Institute.

Nakatani, L. H., \& DuKes, K. D. (1977). Locus of segmental cues for word juncture. Journal of the Acoustical Society of America, 62, 714-719.

Newman, R. S., Sawusch, J. R., \& Luce P. A. (1997). Lexical neighborhood effects in phonetic processing. Journal of Experimental Psychology: Human Perception \& Performance, 23, 873-889.

NorRIS, D. (1994). Shortlist: A connectionist model of continuous speech recognition. Cognition, 52, 189-234.

Norris, D., McQueen, J. M., \& Cutler, A. (1995). Competition and segmentation in spoken word recognition. Journal of Experimental Psychology: Learning, Memory, \& Cognition, 21, 1209-1228.

Norris, D., McQueen, J. M., Cutler, A., \& Butterfield, S. (1997). The possible-word constraint in the segmentation of continuous speech. Cognitive Psychology, 34, 191-243.

Otake, T., Hatano, G., Cutler, A., \& Mehler, J. (1993). Mora or syllable? Speech segmentation in Japanese. Journal of Memory \& Language, 32, 258-278.

PitT, M. A., \& McQueEn, J. M. (1998). Is compensation for coarticulation mediated by the lexicon? Journal of Memory \& Language, 39, 347-370.

Pitt, M. A., \& SAmuel, A. G. (1995). Lexical and sublexical feedback in auditory word recognition. Cognitive Psychology, 29, 149-188.

QuENÉ, H. (1989). The influence of acoustic-phonetic word boundary markers on perceived word segmentation in Dutch. Unpublished doctoral dissertation, University of Utrecht.

QUENÉ, H. (1992). Integration of acoustic-phonetic cues in word segmentation. In M. E. H. Schouten (Ed.), The auditory processing of speech: From sounds to words (pp. 349-355). Berlin: Mouton de Gruyter.

QuenÉ, H. (1993). Segment durations and accent as cues to word segmentation in Dutch. Journal of the Acoustical Society of America, 94, 2027-2035.

Roach, P., Knowles, G., Varadi, T., \& Arnfield, S. (1993). MARSEC: A machine-readable spoken English corpus. Journal of the International Phonetic Association, 23, 47-53.
Saffran, J. R., Aslin, R. N., \& Newport, E. L. (1996). Statistical learning by 8-month-olds. Science, 274, 1926-1928.

Saffran, J. R, Newport, E. L., \& Aslin, R. N. (1996). Word segmentation: The role of distributional cues. Journal of Memory \& Language, 35, 606-621.

Suomi, K., McQueen, J. M., \& Cutler, A. (1997). Vowel harmony and speech segmentation in Finnish. Journal of Memory \& Language, 36, 422-444.

TAFT, M. (1986). Lexical access codes in visual and auditory word recognition. Language \& Cognitive Processes, 1, 297-308.

Turk, A. E., Jusczyk, P. W., \& Gerken, L. A. (1995). Do Englishlearning infants use syllable weight to determine stress? Language \& Speech, 38, 143-158.

Tyler, L. K., \& WeSSEls, J. (1983). Quantifying contextual contributions to word-recognition processes. Perception \& Psychophysics, 34, 409-420.

Tyler, L. K., \& Wessels, J. (1985). Is gating an on-line task? Evidence from naming latency data. Perception \& Psychophysics, 38, 217-222.

Vitevitch, M. S., \& LucE, P. A. (1998). When words compete: Levels of processing in spoken word recognition. Psychological Science, 9, 325-329.

Vitevitch, M. S., \& LucE, P. A. (1999). Probabilistic phonotactics and neighborhood activation in spoken word recognition. Journal of Memory \& Language, 40, 374-408.

Vitevitch, M. S., Luce, P. A., Charles-Luce, J., \& Kemmerer, D. (1997). Phonotactics and syllable stress: Implications for the processing of spoken nonsense words. Language \& Speech, 40, 47-62.

Vroomen, J., \& DE Gelder, B. (1995). Metrical segmentation and lexical inhibition in spoken word recognition. Journal of Experimental Psychology: Human Perception \& Performance, 21, 98-108.

Vroomen, J., Tuomainen, J., \& DE Gelder, B. (1998). The roles of word stress and vowel harmony in speech segmentation. Journal of Memory \& Language, 38, 133-149.

ZWITSERLOOD, P. (1989). The locus of the effects of sentential-semantic context in spoken-word processing. Cognition, 32, 25-64.

\section{NOTES}

1. The strongest facilitatory effect in segmentation might be expected for strings that are frequent at word edges and infrequent word-internally (John Kingston, personal communication, April 24, 1999).

2. Onset, nucleus, and coda are used to describe the structure of syllables in phonology (e.g., Booij, 1995). Each syllable consists of an obligatory vocalic part (the nucleus), preceded by zero or more consonants (the onset) and followed by zero or more consonants (the coda).

3. At present, there is no corpus of spoken Dutch available for the direct computation of frequencies of occurrence of diphones in speech. Instead, diphone frequencies from the CELEX corpus of written language were computed, using the phonological transcription of each word and the written word frequency. Correlation analyses between the nonzero diphone probabilities taken from the English CELEX lexicon and those taken from the MARSEC corpus of spoken English (Roach, Knowles, Varadi, \& Arnfield, 1993) have shown that the CELEX diphone frequencies are reasonable estimates of spoken frequencies $[r(1,237)=$ $.74, p<.001]$.

4. Typically, both by type and token, syllable and word positionspecif ic frequencies of $\mathrm{CV}$ and VC strings are highly correlated. Furthermore, instances in which word and syllable frequencies diverge tend to have a specific linguistic status. High syllable frequencies combined with low word frequencies are typical for CV strings that are common final syllables, such as plural inflections in Dutch. Conversely, low syllable frequencies with high word frequencies are typical for CV strings that are common first syllables-for instance, the past participle prefix /xə/. Asymmetries between type and token counts are mostly caused by CV and VC segments that form function words in Dutch, such as /də/. The use of the intersection of the four sets, rather than the use of a single frequency measure, was motivated by this observation. Since the main aim was to investigate the role of sequential probabilities, confounds with higher level linguistic information-for instance, the potential role of function words and morphemes in segmentation-were avoided. 
5. A full list of the diphone sequences used in the experiments, together with their frequencies of occurrence, is available from the author on request.

6. This is also supported by the lexical neighborhood characteristics of the materials that were used in Experiments 1-3. The average frequencyweighted lexical neigborhood density measures (see Newman, Sawusch, $\&$ Luce, 1997, for the complete procedure) were calculated per condition for both the nonword contexts (high-probability preceding context, $36.6[S D=20.0]$; low-probability preceding context, $15.9[S D=$ $5.6]$; high-probability following-target context, $24.6[S D=14.6]$; low- probability following-target context, $15.9[S D=9.5]$ ) and the target words (initial, 42.8 [ $S D=15.2]$; final, $44.5[S D=16.9]$ ).

7. At a later stage, subjective frequency ratings (on a scale from 1 to 7) were collected from 30 subjects for all the target words that were used in Experiments 4, 5, 6, and 7. These ratings were reasonably correlated with the CELEX frequencies $[r(72)=.60, p<.001]$, and, more important, the targets were well balanced in each experiment (Experiments $4+6$, high-probability mean rating $=4.4[S D=1.4]$, low-probability mean rating $=4.5[S D=1.3]$; Experiments 5+7, high-probability mean rating $=4.5[S D=1.1]$, low-probability mean rating $=4.3[S D=1.1])$.

APPENDIX A

Target-Bearing Stimuli Used in Experiments 1, 2, and 3

\begin{tabular}{|c|c|c|c|c|c|}
\hline \multicolumn{3}{|c|}{ Initial Targets, Experiment $1+2$} & \multicolumn{3}{|c|}{ Final Targets, Experiment $1+3$} \\
\hline High & Low & Translation & High & Low & Translation \\
\hline bok-dif & bok-dous & goat & beel-deuk & buul-deuk & dent \\
\hline ham-dil & ham-douf & ham & seel-douche & suul-douche & shower \\
\hline kap-dirm & kap-doum & cap & kweel-rib & wuul-rib & rib \\
\hline long-dir & long-doup & lung & vreel-rang & muul-rang & rank \\
\hline zaag-dils & zaag-douk & saw & breel-teug & tuul-teug & $\operatorname{sip}$ \\
\hline big-moof & big-nuif & piglet & gan-ram & goum-ram & ram \\
\hline duif-mool & duif-nuim & pigeon & lan-riem & loun-riem & belt \\
\hline pet-moon & pet-nuip & hat & tan-lap & toun-lap & rag \\
\hline gif-moop & gif-nuik & poison & stan-leus & woun-leus & slogan \\
\hline juf-mools & juf-nuig & nanny & nan-lood & noun-lood & lead \\
\hline kiem-vam & kiem-guum & seed & fag-pauw & feug-pauw & peacock \\
\hline duim-varf & duim-guuf & thumb & kag-put & veug-put & well \\
\hline dam-vap & dam-guup & dam & tag-kuif & peug-kuif & forelock \\
\hline rum-vag & rum-guug & rum & zwag-kus & neug-kus & kiss \\
\hline kam-vams & kam-guun & comb & knag-mug & weug-mug & mosquito \\
\hline boon-waam & boon-wuim & bean & kaat-goot & gouk-goot & gutter \\
\hline deun-waaf & deun-wuig & tune & taat-geul & louk-geul & gully \\
\hline map-waamt & map-wuip & folder & zwaat-mus & wouk-mus & sparrow \\
\hline nul-waaft & nul-wuik & zero & knaat-non & stouk-non & nun \\
\hline tor-waapt & tor-wuin & beetle & snaat-gips & nouk-gips & plaster \\
\hline bil-wam & bil-zeuk & buttock & get-fuik & stuup-fuik & fyke \\
\hline bon-wap & bon-zeut & receipt & ket-mouw & duup-mouw & sleeve \\
\hline duin-wan & duin-zeun & dune & tet-mol & puup-mol & mole \\
\hline pap-wamt & pap-zeus & mash & klet-nut & luup-nut & utility \\
\hline lam-waps & lam-zeunt & lamb & stet-nok & muup-nok & ridge \\
\hline peuk-wif & peuk-guif & butt & tat-kok & deup-kok & cook \\
\hline pil-wing & pil-guik & pill & snat-kies & geup-kies & molar \\
\hline lol-wimt & lol-guip & fun & brat-cape & leup-cape & cape \\
\hline jeuk-wift & jeuk-guin & itch & grat-nis & meup-nis & niche \\
\hline sap-wifs & sap-guim & juice & smat-jack & neup-jack & jacket \\
\hline sein-voof & sein-veur & signal & fon-lus & duun-lus & loop \\
\hline tang-vook & tang-veus & pliers & gon-loep & buun-loep & lens \\
\hline mam-vool & mam-veul & mom & lon-rit & kuun-rit & ride \\
\hline ring-voom & ring-veuk & ring & mon-lek & muun-lek & leak \\
\hline loon-voon & loon-veut & wages & kron-roos & vuun-roos & rose \\
\hline pol-vof & pol-feur & clump & stein-rek & deum-rek & rack \\
\hline tol-vom & tol-feul & toll & nein-wol & geum-wol & wool \\
\hline zang-von & zang-feuk & song & slein-wok & leum-wok & wok \\
\hline lak-voft & lak-feus & varnish & smein-doek & meum-doek & towel \\
\hline kuip-voms & kuip-feukt & barrel & krein-bek & neum-bek & snout \\
\hline
\end{tabular}


APPENDIX B

Target-Bearing Stimuli Used in Experiments 4 and 5

\begin{tabular}{|c|c|c|c|}
\hline $\begin{array}{c}\text { High } \\
\text { Probability }\end{array}$ & $\begin{array}{c}\text { Target } \\
\text { Translation }\end{array}$ & $\begin{array}{c}\text { Low } \\
\text { Probability }\end{array}$ & $\begin{array}{c}\text { Target } \\
\text { Translation }\end{array}$ \\
\hline $\begin{array}{l}\text { drum-baaf } \\
\text { dief-beem } \\
\text { pus-bif } \\
\text { spies-bouf } \\
\text { kroos-daaf } \\
\text { pluis-deup } \\
\text { vlas-doum } \\
\text { slag-duip } \\
\text { speen-fiek } \\
\text { kluis-foek } \\
\text { pauw-gam } \\
\text { koek-heem } \\
\text { kap-juif } \\
\text { muis-ruuf } \\
\text { kwaal-suum }\end{array}$ & $\begin{array}{l}\text { Initial Targ } \\
\text { drum } \\
\text { thief } \\
\text { pus } \\
\text { skewer } \\
\text { duckweed } \\
\text { fluff } \\
\text { flax } \\
\text { beat } \\
\text { teat } \\
\text { safe } \\
\text { peacock } \\
\text { cake } \\
\text { cap } \\
\text { mouse } \\
\text { disease }\end{array}$ & $\begin{array}{l}\text { Experiment } 4 \\
\text { creme-baag } \\
\text { sleuf-beep } \\
\text { hasj-bim } \\
\text { creche-boug } \\
\text { gleuf-daam } \\
\text { vleug-deut } \\
\text { teug-dous } \\
\text { spuug-duis } \\
\text { clown-fiet } \\
\text { douche-foes } \\
\text { kieuw-gan } \\
\text { truc-heeg } \\
\text { heup-juik } \\
\text { zeug-ruus } \\
\text { beul-suun }\end{array}$ & $\begin{array}{l}\text { cream } \\
\text { groove } \\
\text { hash } \\
\text { daycare } \\
\text { slot } \\
\text { breath } \\
\text { sip } \\
\text { spit } \\
\text { clown } \\
\text { shower } \\
\text { gills } \\
\text { trick } \\
\text { hip } \\
\text { sow } \\
\text { hangman }\end{array}$ \\
\hline $\begin{array}{l}\text { kaaf-zeem } \\
\text { baam-dis } \\
\text { beeg-dok } \\
\text { jeel-vaas } \\
\text { beem-dot } \\
\text { deep-wees } \\
\text { teuf-wig } \\
\text { peum-vaat } \\
\text { meun-zeef } \\
\text { deus-wal } \\
\text { fiem-gal } \\
\text { hien-galg } \\
\text { bif-dam } \\
\text { goem-vat } \\
\text { boof-gans } \\
\text { bouk-ven } \\
\text { boum-vork } \\
\text { kuuf-gast } \\
\text { guuk-zeep } \\
\text { buum-vel }\end{array}$ & $\begin{array}{l}\text { Final Targe } \\
\text { chammy } \\
\text { dish } \\
\text { dock } \\
\text { vase } \\
\text { dowry } \\
\text { orphan } \\
\text { wedge } \\
\text { dishes } \\
\text { sieve } \\
\text { shore } \\
\text { gall } \\
\text { gallows } \\
\text { dam } \\
\text { barrel } \\
\text { goose } \\
\text { puddle } \\
\text { fork } \\
\text { guest } \\
\text { soap } \\
\text { skin }\end{array}$ & $\begin{array}{l}\text { Experiment } 5 \\
\text { taaf-zeur } \\
\text { daam-jazz } \\
\text { peeg-junk } \\
\text { weel-vouw } \\
\text { deem-dauw } \\
\text { heep-woud } \\
\text { veuf-jicht } \\
\text { veum-fout } \\
\text { veup-fohn } \\
\text { meus-jack } \\
\text { siem-geul } \\
\text { pien-geur } \\
\text { tif-jeans } \\
\text { loem-fuik } \\
\text { toof-shirt } \\
\text { fouk-cheque } \\
\text { foum-zeug } \\
\text { puuf-sjeik } \\
\text { suuk-chef } \\
\text { puum-saus }\end{array}$ & $\begin{array}{l}\text { nag } \\
\text { jazz } \\
\text { junkie } \\
\text { fold } \\
\text { dew } \\
\text { forest } \\
\text { gout } \\
\text { error } \\
\text { hairdryer } \\
\text { jacket } \\
\text { gully } \\
\text { smell } \\
\text { jeans } \\
\text { fyke } \\
\text { shirt } \\
\text { check } \\
\text { sow } \\
\text { sheik } \\
\text { boss } \\
\text { sauce }\end{array}$ \\
\hline
\end{tabular}

(Manuscript received February 17, 1999; revision accepted for publication October 2, 2000.) 